\title{
Models of intercultural competences in practice
}

\section{Eva Reid}

Department of Language Pedagogy and Intercultural StudiesConstantine the Philosopher University in Nitra, Slovakia

\author{
Email address: \\ ereid@ukf.sk
}

\section{To cite this article:}

Eva Reid, Models of Intercultural Competences in Practice. International Journal of Language and Linguistics,

Vol. 1, No. 2, 2013, pp. 44-53. doi: 10.11648/j.ij11.20130102.12

\begin{abstract}
Research in the area of intercultural competences has become increasingly popular. Scholars have been developing theoretical models for acquiring and evaluating intercultural competences, looking for connections between interdisciplinary subjects, and researching developments of intercultural competences in foreign relations, immigration, politics, education, commerce and health care. When new models are developed, they must be tested in diverse contexts in order to validate them and determine their intercultural relevance. This paper not only introduces several models of intercultural communication but also presents an overview of the studies performed on them, analyses their strengths and weaknesses and makes suggestions for further research. King and Magolda's (2005) Developmental Model of Intercultural Maturity, Bennett's (1993) Developmental Model of Intercultural Sensitivity, Gullahorn and Gullahorn's (1963) W Model of Acculturation and Re-acculturation and Lysgaard's (1955) U Curve Hypothesis" are addressed and results testing the models are presented here.
\end{abstract}

Keywords: Intercultural Competences, Intercultural Adjustment, Intercultural Sensitivity, Intercultural Maturity

\section{Introduction}

Intercultural communication and intercultural communicative competences have lately been hot topics for scholars, educators, psychologists, politicians and even businessmen. Consequently, numerous models of intercultural competences have been developed. They are often divided into the following types: casual path, compositional, co-orientational, adaptational and developmental. The paper briefly describes various types of intercultural competences, presents studies testing different developmental models, critically analyses them and makes suggestions for further research.

Casual path models attempt to represent intercultural competence as a theoretical linear system. They tend to form variables at a downstream location, which influences and is influenced by moderating and mediating variables that in turn influence the upstream variables. The best known is the Model of Intercultural Communicative Competence by Arasaratnam (2005) [1].

Compositional models identify components of competence without specifying relations among the components. They list relevant traits, characteristics, and skills that are supposed to be productive for competent intercultural interaction. An example of the compositional model is Deardorff's (2009) [2] Pyramid Model of Intercultural Competence.

Co-orientation models of intercultural communication are concerned with conceptualizing the interactional achievement of intercultural understanding (perceptual accuracy, empathy, clarity, overlap of meaning systems). They are primarily focused on communicative mutuality and shared meanings. The representational models discussed here are the Intercultural Interlocutor Competence Model by Fantini (1995) [3] and the Intercultural Competence Model by Byram (1997) [4].

Adaptation models either envision multiple interactants in the process, or emphasize interdependence of multiple interactants by modelling the process of mutual adjustment. Adaptational models can be represented by Berry's (1998) [5] Attitude Acculturation Model.

Developmental models are concerned with the stages of progression or maturity in acquiring intercultural competence. The best known models are the developmental Model of Intercultural Maturity by King and Baxter Magolda (2005) [6], the U Curve Hypothesis Model by Lysgaard's (1995) [7], the extended W Model of Acculturation and Re-acculturation by Gullahorn and Gullahorn (1963) [8] and the Developmental Model of Intercultural Sensitivity (DMIS) by Bennett (1993) [9]. Developmental models recognize that intercultural 
competences develop over time. The claim is that the learners are capable of becoming more competent through ongoing interaction, which produces greater co-orientation, learning, and incorporation of respective cultural perspectives.

The aim of this paper is to look deeper into different developmental models of intercultural competences, present research studies based on the chosen models, critically analyse them and make suggestions for further research.

\section{Methodology}

\subsection{Meta-analyses}

The method chosen for my study is meta-analyses, which can be simply described as analysis of other analyses. According to Cohen (2007) [10] meta-analyses are often done statistically, but qualitative analyses are also advocated. The aim is to collect, combine and compare studies dealing with similar issues. In this case, the studies are analyzed qualitatively. Each of the three developmental models of intercultural competences - Model of Intercultural Maturity [6], W Model of Acculturation and Re-acculturation [8] and Developmental Model of Intercultural Sensitivity [9] - are represented here by three studies and these are analyzed. The studies are ranging from the year 2000 to the year 2011 and map various research studies supporting the mentioned models. The aim is to see whether there are visible changes noticeable in the eleven year span of research in the area of intercultural competences and if there are any generalizations possible in development of intercultural competences.

\section{Developmental Models of Intercultural Maturity}

\subsection{Theoretical Background and Origin of the Model of Intercultural Maturity}

In 2005, King and Baxter Magolda [6] developed one of the best known models - Model of Intercultural Maturity, which was based on Kegan's (1994) [11] Model of Lifespan Development. According to Kegan [11], mature individuals are better equipped to approach and respond to complex tasks in life. Individuals organise their own lives, trying to find a balance between external influences, individual interests and the interests of others around them. Kegan's [11] model is holistic and integrates three dimensions of development (cognitive, intrapersonal and interpersonal). He claimed that the development of all three dimensions was necessary in order to be able to use one's skills. King and Baxter Magolda's [6] model of intercultural maturity is also based on three dimensions: cognitive (to understand cultural differences), intrapersonal (to accept and not feel threatened by cultural differences) and interpersonal (to be sensitive and to function interdependently with diverse others). Each dimension includes the initial, intermediate and mature levels of intercultural development. According to this model, learners progress during intercultural learning from ethnocentric understandings of other cultures to the ethnorelative comprehension and appreciation. The framework of this model takes the form of a 3 x 3 matrix, linking domains of development (cognitive, intrapersonal, and interpersonal) with three levels of development (initial, intermediate, and mature). In the process of intercultural learning, the idea is to produce, in the times of increased global interdependence, interculturally competent citizens, who would achieve intercultural maturity in all three dimensions. King and Baxter Magolda's [6] model is multidimensional and describes levels of intercultural maturity. In this framework it is explained how people become increasingly capable of understanding and become interculturally aware and act in an interculturally appropriate way.

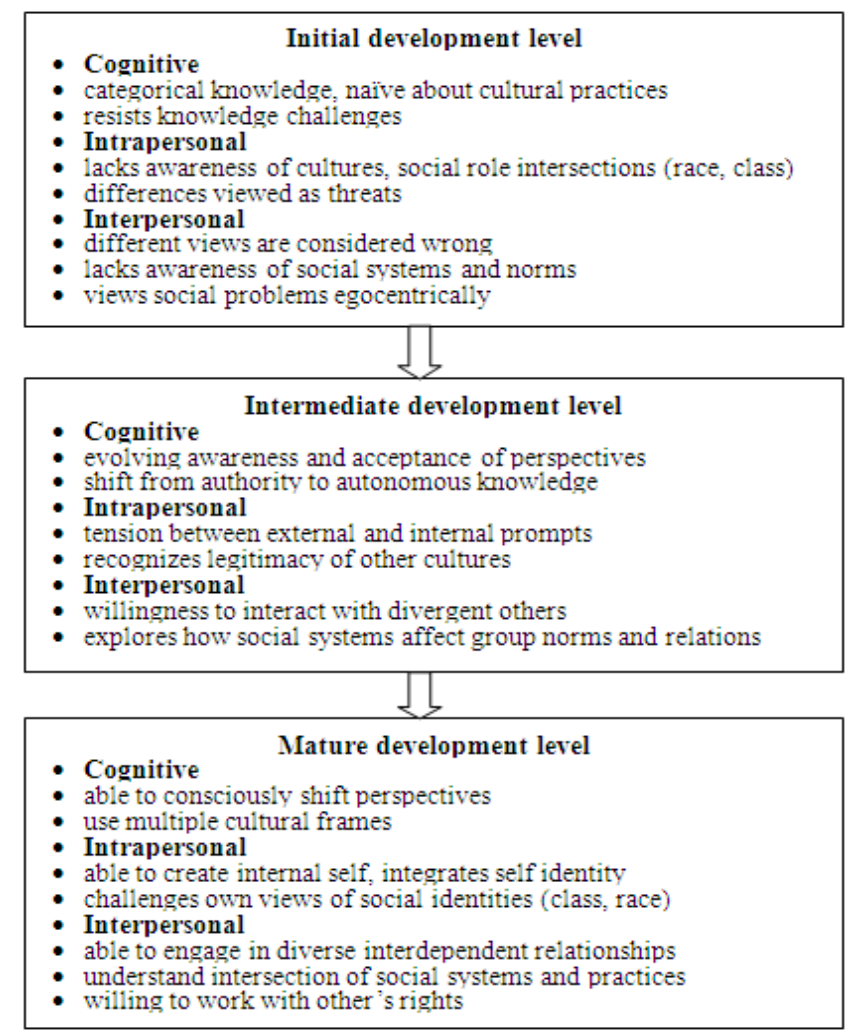

Figure 1: Adapted Developmental Model of Intercultural Maturity [6]

\subsection{Intercultural Maturity of Latin American and White American College Students}

The Model of Intercultural Maturity [6] was developed from the longitudinal studies carried out by Baxter Magolda (2004) [12,13] and Tores (2003) [14]. In their longitudinal studies they conducted interviews with white and Latin American college students at an independent, urban, research university on the East Coast of the USA, which served as the basis of their model of intercultural maturity. These students were interviewed over a long period of time and the data show different stages of the 
development of intercultural maturity. Students at the beginning of the research showed a lack of awareness of one's own identity and values. The white students viewed differences between people as wrong, needed affirmation from dependent relationships with similar others, and showed almost no ability to reflect and deal effectively with differences, which is a key aspect of intercultural maturity. Students of Latino origin or from mixed families encountered segregation: they experienced difficulties connecting with any cultural group, as they were too white for students from countries like Mexico, Puerto Rico, Cuba, Venezuela, Colombia, etc. and too Latino for whites. In the intermediate level of intercultural maturity, the white students started to see and understand multiple realities, and they were not avoiding new relationships with people they would previously avoid. They had moved beyond relationships with those similar to themselves and were exploring differences. The Latin American students moved from the initial feeling of not belonging anywhere to starting to feel bicultural. They recognized the distinction between how other students saw them and how they self-identified. The Latin American students still desired greater approval and acceptance from Latinos, which they tried to achieve by exploring Latino culture and learning the language. In the mature level of intercultural maturity, the Latino American students showed the ability to understand different cultural orientations, accept their own cultural identity and how it differs from others and encourage others to accept the differences. The greatest ability these students showed was the skill to shift perspectives and use multiple cultural frames to engage in meaningful relationships with diverse others without seeking their approval. White students showed maturity after staying in a close relationship with non-whites. These students demonstrated great sensitivity and a desire to understand different cultures, and recognized the need to define their beliefs internally and define their role in the larger world.

These examples show ideal states of three levels of intercultural development, and it cannot be expected that every individual would go through the stages the same way and would become interculturally mature. The process is highly individual. Further, the studies were carried out with college students of an independent, urban, research university - young people, who are more flexible and malleable. It would be necessary to test this model with adults living or working in multicultural environments to prove the applicability of this model to the greater public.

\subsection{Intercultural Trainings of Employees}

As mentioned, there is currently a great demand for people who are interculturally mature. Colleges are expected to prepare interculturally competent graduates, and companies also organise intercultural trainings for their employees. Ortiz and Rhoads (2000) [15] suggest a five step framework for multicultural training, which should bring an individual towards intercultural maturity: understanding culture, learning about cultures, deconstructing white culture, recognizing the legitimacy of other cultures and developing their multicultural outlook into the mature level of intercultural maturity. Activities for each step engage trainees in exploring and gradually reformulating how they see the world (cognitive), how they relate to others (interpersonal) and how they see themselves (intrapersonal).

Another four stage programme for intercultural training was developed by Schoem and Hurtado (2001) [16]. The training is based on dialogues, which are structured to explore trainees' own experiences and assumptions, to develop a shared vocabulary around issues of social identities, prejudice, discrimination, and privilege, to focus dialogues on hot topics such as separation, self-segregation and racism, and to plan actions and build alliances. The authors claim that the results of the intercultural dialogue trainings are positive, reducing discrimination, stereotyping, prejudice and anxiety about intercultural contact, and increasing social awareness.

However, there are no concrete results from empirical research available to back up these assertions, but application of these models of intercultural trainings for employees would be very topical and beneficial in further research.

\subsection{Intercultural Maturity Development of Adult Learners}

Stickler and Emke (2011) [17] conducted a project LITERALIA, which was funded by the European Union and it was to observe adults' language learners development of intercultural maturity [6]. The aim of the project was to connect adult language learners (229) from four different countries (UK, Germany, Italy and Poland) and analyse participants' intercultural learning and show development of intercultural maturity. The respondents were working in tandem and were to give mutual support to each other in learning one another's language and culture through online communication. Qualitative data was collected by observation, feedback and interviews and analysed to present a description of adults' experiences through intercultural learning. The findings show that the personal learning partner became the central figure and the development of friendship was the central point, and the intercultural exchange was not the most important target. The tandem partner was the trusted source of information and intercultural exploration. Learners would venture sometimes into uncomfortable zones of intrapersonal development, examining and accepting their own and other cultures in context. The researches claim that the intercultural maturity depends on social interaction and it is not a change in personality or life style, but an integration of new perspectives into the everyday life of the mature intercultural learner. The study focused on how interactions shaped and developed intercultural competences. Reasons for failure were not researched.

Even though the research sample was big in this case, 
the study proves that research done on intercultural issues is highly individual and cannot be generalized.

\begin{tabular}{|c|c|c|}
\hline \multirow{3}{*}{$\begin{array}{l}\text { Ethnocentric } \\
\text { stages }\end{array}$} & Denial & $\begin{array}{l}\text { one own's culture is viewed as the } \\
\text { only real one, } \\
\text { other cultures are avoided, } \\
\text { people are indifferent to cultural } \\
\text { difference, can act aggressively }\end{array}$ \\
\hline & Defense & $\begin{array}{l}\text { one own's culture is viewed as the } \\
\text { only good one, } \\
\text { world is organized: "us and them", } \\
\text { "we" are superior and "they" are } \\
\text { inferior, } \\
\text { people are threatened by cultural } \\
\text { differences, they are highly critical } \\
\text { of other cultures, regardless if } \\
\text { "they" are hosts or guests }\end{array}$ \\
\hline & Minimalization & $\begin{array}{l}\text { one own's culture is viewed as } \\
\text { universal, } \\
\text { other cultures are trivialized or } \\
\text { romanticized, } \\
\text { people expect similarities, may } \\
\text { become insistent about correcting } \\
\text { others' behaviour to match their } \\
\text { expectations }\end{array}$ \\
\hline \multirow{3}{*}{$\begin{array}{l}\text { Ethnorelative } \\
\text { stages }\end{array}$} & Acceptance & $\begin{array}{l}\text { one's own's culture is viewed as just } \\
\text { one of a number of equally complex } \\
\text { worldviews, } \\
\text { acceptance does not mean } \\
\text { agreement, cultural differences may } \\
\text { be judged negatively, } \\
\text { people are curious and respectful } \\
\text { toward cultural differences }\end{array}$ \\
\hline & Adaptation & $\begin{array}{l}\text { experience of another culture } \\
\text { benefits perception and behaviour } \\
\text { appropriate to that culture, } \\
\text { one's worldview is expanded to } \\
\text { include constructs from other } \\
\text { worldviews, } \\
\text { people are able to look at the world } \\
\text { "through different eyes" and may } \\
\text { intentionally change their behaviour } \\
\text { to communicate more effectively in } \\
\text { another culture }\end{array}$ \\
\hline & Integration & $\begin{array}{l}\text { one's experience of self is expanded } \\
\text { to include the movement in and out } \\
\text { different cultures }\end{array}$ \\
\hline
\end{tabular}

Figure 2: Adapted Developmental Model of Intercultural Sensitivity [9]

\section{Developmental Model of Intercultural Sensitivity}

\subsection{Basic Principles of the Model of Intercultural Sensitivity}

Another developmental model was designed by Bennett (1993) [9] and deals with the development of intercultural communicative competence of individuals. The Developmental Model of Intercultural Sensitivity (DMIS) synthesises attitudes, skills and knowledge with which researchers and trainers in intercultural communications and foreign languages have long been familiar. The basis for this model were Bennett's [9] somewhat predictable observations of individuals in the process of becoming competent in intercultural communications. Using concepts from cognitive psychology and constructivism, he organized these observations into six stages moving from cultural naivety to cultural sophistication. The initial three stages are ethnocentric (one's own culture is experienced as central to reality in some way) and the final three stages are ethnorelative (one's own culture is experienced in the context of other cultures). Bennett's [9] model of cultural learning is situated within the domain of subjective culture, which is sometimes referred to as "small c culture." It generally receives less attention and yet is far more significant. Subjective culture consists of invisible components (assumptions, values and beliefs) and a visible component (behaviour). Bennett [9] is right to believe that understanding objective culture may create knowledge but does not necessarily generate competence.

\subsection{Language Learning and Intercultural Sensitivity}

Durocher (2007) [18] applied Bennett's [9] Developmental Model of Intercultural Sensitivity (DMIS) in a study on freshman U.S. French language students. Three classes were pre-tested with the Intercultural Development Inventory to evaluate their level of sensitivity to cultural differences. The reason for this research was to determine if Bennett's [9] recommendation to address denial and defence issues in elementary-level language classes was warranted, to incorporate intercultural training activities to the students' level of sensitivity as revealed by the inventory, and to post-test students at the end of semester to see if a noticeable increase in the level of sensitivity had been observed. The pre-tests were carried out on all the students: those who would have intercultural training and those who would not. Even though it seemed that the students were starting with different levels of sensitivity, the reality was that in both groups the majority of students were identified in one of the ethnocentric levels of sensitivity. In the control group, $71 \%$ of the students were in denial or the defence stage of sensitivity, compared to $65 \%$ of the students in the group that was to receive the intercultural training. A total of five intercultural training activities were planned and implemented during one semester. These activities were spread out at even intervals during the semester, with each activity taking about 30 minutes. All activities were addressed to the denial and defence issues. The outcome of the post-test with the class that received the training are as expected. Even though there was not a considerable shift from ethnocentric to ethnorelative levels of sensitivity, the results were still encouraging. Most students moved a level higher in the framework of intercultural sensitivity. The biggest growth was in the minimalization stage from 31 to $54 \%$. Still, $47 \%$ of the students remained in the denial or the defence stage of sensitivity. Overall, most students were still ethnocentric, but a shift toward the ethnorelative stages of sensitivity could be observed. The class that received no intercultural training experienced some changes too. The most noticeable was the shift of three students from minimalization to defence stage.

This points to the fact that language classes themselves do not automatically train students toward ethnorelativism, but they can in reverse provoke defence issues and make 
students more ethnocentric. Durocher [18] notes that if foreign language educators do not effectively address the negative attitudes of their students, they run the risk of doing more harm than good. This claim can only be agreed upon when taking into account that ethnorelativism does not come naturally hand in hand with foreign language education, and if intercultural issues are not included in foreign language lessons, then in extreme cases a reverse process can occur in which students become even more ethnocentric than before. This finding is quite alarming, and educators, especially foreign language teachers, should be aware of the danger, that omitting intercultural training can cause.

\subsection{Model of Intercultural Consciousness for Leaders}

Bennett's [9] Developmental Model of Intercultural Sensitivity (DMIS) was also applied to Karim's (2003) [19] Developmental Progression Model of Intercultural Consciousness for Leaders. This model provides a framework for understanding how people make sense of the world and engage in leadership actions at different levels of intercultural consciousness. The author [19] stresses the need for business leaders to possess intercultural sensitivity, as the physical boundaries in the world shrink but the psychological boundaries are still deeply divided by race, ethnicity, ideology, politics, region and inequality. The increasing globalization of business does not necessarily mean that cultural differences are diminishing. Businesses have physical offices in several countries, work on multinational projects and deal with customers, counterparts and employees who are culturally diverse. Karim [19] claims that there has never before been such an important need for interculturally competent leaders as there is today. There is no escaping intercultural contact in today's "connective era," and it is evident that notions of leadership are outdated. The author [19] discusses the issues of intercultural consciousness in the context of leadership, identifies necessary areas of knowledge and skills associated with intercultural proficiency, and offers a model of intercultural consciousness for leaders. He [19] distinguishes the difference between intercultural competence and intercultural consciousness in one critical dimension - ethical responsibility. He [19] notes that interculturally competent leaders can act either ethically or unethically.

Although intriguing, empirical research is needed before the proposed model is applied to leaders. As was mentioned before, the interculturally competent employees and employers are becoming a necessity in the today's global world. Several models and suggestions have been proposed, but very little research was done in this area. However, there is a scope for further research and this model of intercultural consciousness for leaders would be a very beneficial topic to explore.

\subsection{Case Study of a Pre-service Teacher and her Intercultural Sensitivity Development}

Marx (2008) [20] carried out a case study with a pre-service teacher and her intercultural sensitivity development during one semester education study abroad program in England. This research is based on the Bennett's [20] Developmental Model of Intercultural Sensitivity (DMIS) and described a development of the respondent's transition from ethnocentric to ethnorelative mindset. The aim of the study was to seek understanding of the ways international experiences influence teachers' intercultural development and find if international experiences prepare culturally responsive teachers. The respondent was an American pre-service teacher, who took an internship at a secondary school in a lower-income neighbourhood in London with a multicultural population of 1,400 students (ages 11-19). The respondent spent twenty hours a week as a mathematics support teacher. Qualitative data sources and collection methods namely field work, in-depth interviews and document analyses, helped the researcher to uncover the respondent's subjective experiences within the context of an intercultural environment. The findings show that at the beginning, the respondent had a slightly ethnocentric approach and showed characteristics from the minimalization stage of DMIS [9] This can be interpreted that she was interested in learning about other cultures, but her understanding was unsophisticated and she was seeking individual and psychological explanations for differences. Towards the end of the respondents stay abroad she adopted a more ethnorelative approach, and she moved to the acceptance stage of DMIS [9]. This means that she developed more sophisticated cultural-constructs, explored her own cultural identity, accepted and recognized fundamental cultural differences in herself and others, and was actively seeking intercultural experiences.

As mentioned in methodology, this study is to provide an in-depth understanding of a particular case and not to make generalizations. It can be concluded, that this particular case proves the Bennett's Developmental Model of Intercultural Sensitivity [9], as the respondent has under the influence of intercultural environments moved from ethnocentric to ethnorelative stages of intercultural sensitivity. The researcher thinks that this is because the respondent was an outsider within the cultural context, where her cultural values no longer applied, and she was forced to become more conscious of host culture and cultural differences. Still, it can only be agreed with the researcher, that this study provides understanding of the single case and cannot be generalized.

\section{W Model of Acculturation and Re-acculturation}

\subsection{Principles of the $U$ Curve Hypothesis and the W Model of Acculturation and Re-acculturation}

Another developmental model adapts the concept of cultural shock to a stage of cultural adjustment. Gullahorn 
and Gullahorn [8] extended Lysgaard's [7] $U$ Curve Hypothesis to the $W$ Model of Acculturation and Re-acculturation to address post-return readjustment problems. The model proposes that there is a multistage wave response of adjustment and satisfaction in response to acculturation. This model especially reflects those people who went to live abroad, or spend a long time in a different culture and the return home. The model states that people first experience a honeymoon stage, when experiences are relatively positive in the context of a halo effect of novelty. An abrupt fall follows and results in a hostility stage, when the confrontation of differences becomes apparent. Efforts to adapt continue, and interactants recover and are able to recognize the humorous nature of some differences between cultures. Interactants then reach a level at which they feel in sync with the cultural environment. People who spend a long time in another culture are expected to experience some degree of uncertainty as they face the prospects of returning home, abandoning their new found sense of relative comfort. When returning home, people often experience re-entry cultural shock as they find themselves trying to re-integrate to their home culture. Eventually they experience re-socialization with their home culture.

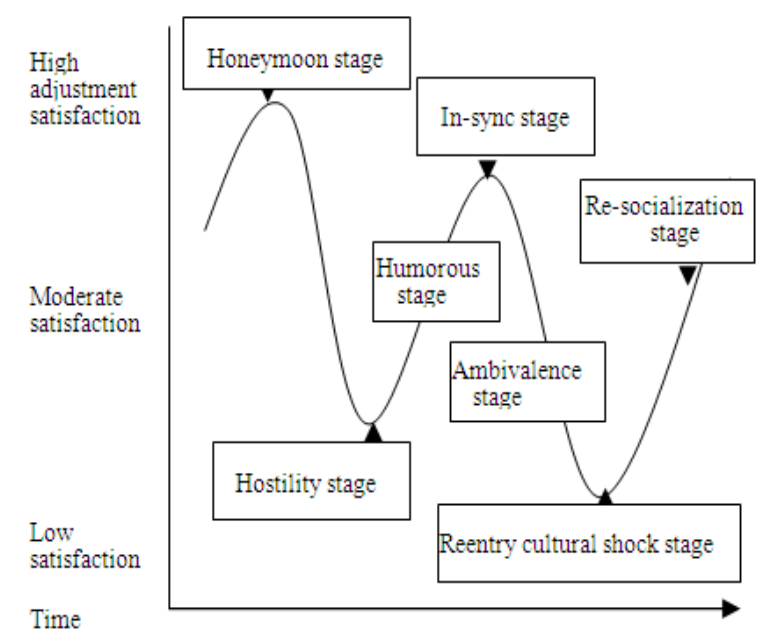

Figure 3: W Model of Acculturation and Re-acculturation [8]

\subsection{The U Curve Hypothesis Model applied to Japanese Students in the UK}

The U Curve Hypothesis Model [7] was applied in Greendland and Brown's (2005) [21] research on Japanese students studying in the United Kingdom for a year. In this study, the attempt was to address the students' psychological well-being during their process of acculturation. The acculturation process can last for days, weeks, years, and even generations. At various points in this process (often in early stages) individuals from minority groups may experience an acculturative stress. Because Japanese and British cultures are so different, also the expectations of Japanese and British nationals might be very different, which consequently may result in considerable adjustments on the part of the Japanese students. The authors [21] predicted that the participants' acculturative stress would increase sharply after their arrival in the UK and then would eventually decrease as they adapted over time (U-curve hypothesis). It is important to consider variations in the degree to which individuals experience acculturative stress, where age, gender, or education might be influencing variables. According to Berry (2002) [22], language ability is the key predictor of adaptation. Individuals who have a good knowledge of the majority language appear to adapt more successfully than those who do not. The researchers [21] also predicted that during acculturation, a higher language ability would be associated with reduced acculturative stress. The participants were 54 Japanese students aged between 18 to 22 years. The students were given a questionnaire on sociocultural items, psychological items, language ability, perceived cultural distance, and the quantity and quality of contact with British nationals. The same questionnaire was given to the students three times over a period of 12 months. Results showing changes across time revealed that acculturative stress increased sharply between Time 1 and 2, and that there was no observed drop in stress between Time 2 and 3, which disproved the full U-curve hypothesis. As expected, the participants' language ability increased significantly, but surprisingly, between Times 1 and 2, higher language ability increased acculturative stress. Later on between Times 2 and 3, the effects of language were more consistent with predictions that higher language ability was associated with less stress. The possible reason for this was unrealistic perceptions of the participants' language abilities upon their arrival to the UK, because the participants were evaluating their own knowledge of English.

The outcomes of this study show that there might be physical, geographical, social and cultural restrictions on acculturation. Rudmin and Ahmadzedeh (2001) [23] criticize acculturation theories for assuming that all acculturative outcomes are achievable. They [23] believe that integration is not always possible because of different cultural practices, which are exclusive (one cannot be both a Christian and a Muslim), or legally restricted (driving on the left or right side of the road).

The outcomes of this research are very limiting because they concern only a group of students from one nationality staying abroad for one year. Many facts in this study were predictable (vast differences between Japanese and UK cultures, or young people being more flexible and adjustable). Also, this research was only based on questionnaires, where data is not always reliable, as noted by the students' evaluation of their own knowledge of English. It would be interesting to apply and compare results of this model on a larger scale in many different settings with people of various cultural backgrounds, different age groups and also lengths and purposes of stays abroad, and to test Lysgaard's [7] U Curve Hypothesis Model or Rudmin and Ahmadzedeh's [23] claim that 
acculturation is not always possible.

\subsection{Re-adjustment of Polish Students to their Home Culture}

Another study conducted by Wielkiewicz and Turkowski (2010) [24] tests Gullahorn and Gullahorn's [8] W Model of Acculturation and Re-acculturation. The study, which was based on an online survey, examined the re-adjustment to home culture of 669 college students who studied abroad. The aim was to compare the adjustment of students who studied abroad with those who did not, and to investigate the impact of study abroad on interpersonal relationships. The vast majority of participants spent one semester abroad. $63 \%$ of the students were females and all of the students were between 18 and 22 years of age. It was predicted that students who spent time abroad would experience greater anxiety or depression than similar students who did not study abroad. The results show that the students who studied abroad reported significantly more scepticism (re-entry shock) regarding their home culture than those students who did not. The longer the students spent abroad, the greater re-entry shock they experienced after returning home. This study supports the W Curve Model of Acculturation and Re-acculturation [8] and previous studies that psychological changes occur after returning from study abroad. The researcher predicted that study abroad would have negative effects on romantic relationships, but the outcomes did not bear this out, as there were no significant differences between the study abroad group and the control group. The reason for this outcome might be the short length of stay abroad or that the participants had not been at home long enough to experience the effects of readjustment and its impact on relationships. An interesting result is that women were less able to cope with anxieties, felt less relaxed and experienced more stress in relationships than men.

This study tested only the re-entry cultural shock of students and did not include the full scale of the W Model of Acculturation and Re-acculturation [8]. It was further limited because the students were of one nationality and stayed abroad for only a few months, which might not be long enough to experience cultural shock. Further, online surveys are fraught with reliability issues. As with the previous study, it would be better to carry out further studies with different nationalities, age groups, professions, lengths of stay and on the full scale of the W Curve Model of Acculturation and Re-acculturation [8] to get relevant results to test the applicability of the model.

\subsection{Adjustment and Re-adjustment of Asian Graduates after studying in Northern Ireland}

Pritchard (2011) [25] published research, which was examining re-integration of Asian students back to their home countries. This study is testing the $\mathrm{W}$ Model of Acculturation and Re-acculturation [8]. The research sample consisted of 12 Taiwanese and 15 Sri Lankan graduates, who did their Master's degree from TEFL in Northern Ireland. The research was conducted by means of interviews with the respondents, who had returned to their home countries to work. The interview began with retrospective analyses of life in Northern Ireland and linked with their feelings upon their return to the home country. The "cultural shock" feelings in the host country were mainly connected to missing their families, food, mother tongue, warm weather, etc. Surprisingly, some of the negative feelings connected to returning to their homes were exactly what they had missed about their own countries on their entry to the United Kingdom: lifestyle, food, and weather. Respondents experienced various levels of difficulties in different areas of re-adaptation to their home culture. The majority of people claimed not to have any personal difficulties on reconnecting with their families within their own culture. Negative feelings were connected with the Sri Lankans perception of the level of development of their home societies (stressful life, crowded places, chaotic traffic). The greatest problems were noticed in conflicting values between modernism and traditionalism or between individualism and collectivism. For example, the respondents were constrained by social and employer's expectations and their newly adopted values could not be transferred unproblematically into their home environments, such as they struggled to introduce innovations to their work places, reduce social distance, or have more democratic relationships. As a conclusion, the respondents were doing well professionally, which presumably reduced the stress of re-entry to their home societies. Good jobs and therefore a defined role in society helped them to reintegrate fast and well. Definitely, the most positive thing noticed by the respondents was the gained independence and ambitious approach to life and work.

This study was concerned with the full scale of the W-curve Model of Acculturation and Re-acculturation [8]. The in-depth interviews with 27 respondents from Asian countries, who lived and studied in the UK bring some interesting results. Overall the respondents did not experience great cultural shock in the foreign county and re-entry cultural shock on returning back home. The reason for reduced cultural shock might be that the respondents lived in Asian communities abroad and that they did not enter the local life (which some of them regretted). Adapting back to their home countries was without any great difficulties, as all the respondents straight away had good jobs, which helped them to re-adapt fast to their home environments.

\section{Conclusion}

This article has focused on the developmental models of intercultural progression, maturity and adjustment in the progress of acquiring intercultural competences because these types of models are most widely applicable. Six studies were analyzed in this paper and each of them supported one of the three developmental models of 
intercultural competences.

The Model of Intercultural Maturity [6] was tested by Baxter Magolda [12,13] and Tores [14] on Latin American and white American college students. The longitudinal studies are reliable, but nevertheless replicability would be difficult with other groups of people Findings from the research showed positive development in intercultural maturity of the respondents, but the research was carried out with college students, who are young, flexible and adaptable, but to make the model applicable to larger groups of people, more research conducted on adults living abroad would be necessary.

The need for interculturally competent employees was reflected by Ortiz and Rhoads [15] in their five step framework for multicultural training and Schoem and Hurtado [16] in their four stage programme for intercultural training for employees. The aim of the training is to reduce discrimination, stereotyping, prejudice and anxiety about intercultural contact and to create positive attitudes and social awareness towards other cultures. However, no relevant research was found to test applicability of these programmes of intercultural maturity, but it would be contributive to carry out research on the intercultural training of employees.

The Development of Intercultural Maturity of adult learners was analysed in a study by Stickler and Emke [17]. Adult learners from four different countries were to work online in tandems, learning language and culture from each other. The aim was to analyse intercultural learning and development of intercultural maturity of the participants. The findings show that development of personal relationships was more important for the learners than intercultural learning. The research dealt with intercultural development of individuals and did not analyse cases where intercultural learning was not successful. Findings from this study show a highly individual development pattern of intercultural competences.

The model of Intercultural Sensitivity [9] was tested by Durocher [18] in a study on American students learning French. One group of language lessons included intercultural training activities to enhance the students' level of sensitivity. The outcomes reveal, that ethnorelativism is not a natural part of foreign language education, and that in extreme cases learners (when no intercultural activities are included in foreign language lessons) can become even more ethnocentric. This proves the fact that intercultural teaching should without doubt be a part of foreign language teaching and that it should be an integral part of teaching reading, listening, speaking and writing and should not be treated as an extra fifth skill (Reid, 2010) [26]. The foreign language teachers should realize the importance of intercultural aspects in their foreign language lessons.

Based on the model of intercultural sensitivity [9], Karim [19] developed a Progression Model of Intercultural Consciousness for Leaders. This model provides a framework of development of intercultural sensitivity and consciousness of leaders. Empirical research testing this model was not found, even though it is a highly current topic. This offers a great chance for further research.

The Model of Intercultural Sensitivity [9] was tested by Marx [20] in a case study of a pre-service teacher spending one semester in London, UK. The aim was to see if international experiences have positive influence on development of intercultural sensitivity of teachers. After one semester of staying abroad, the respondent appeared to move from slightly ethnocentric approach to beginning of ethnorelative mindset. The outcomes of this research followed the stages of the Model of Intercultural Sensitivity [9], but as mentioned before, generalizations cannot be made based on this one case study.

Greendland and Brown [21] applied the U Curve Hypothesis Model [7] in research on Japanese students studying in the UK. The study showed the students' psychological well-being during their process of acculturation. As mentioned before, many findings resulting from the differences between British and Japanese cultures were predictable, due to great differences between the two cultures. Again, the study is limited to two cultures and young students (who are more flexible and adaptable). The suggestion is to conduct a similar type of research on representatives of different cultures, different age groups, length and purpose of their stays abroad, to enrich the applicability of the proposed model.

Another study conducted by Wielkiewicz and Turkowski [21] tests Gullahorn and Gullahorn's [8] W Model of Acculturation and Re-acculturation. The study examined the re-adjustment of Polish students to home culture after studying abroad. The survey tested only the re-entry cultural shock and not the full scale of the W Model of Acculturation and Re-acculturation [8]. Another limitation was the length of stay abroad (average one semester), which may not be long enough to produce pronounced symptoms of cultural shock. Further research on the full scale of the W Model of Acculturation and Re-acculturation [8] would be advisable on representatives of different cultures, age groups, professions and with greater lengths of stay.

Research conducted by Pritchard [25] examines re-integration of Asian students to their home culture after studying in the UK. The study follows the second part of the W Model of Acculturation and Re-acculturation [8] and investigates areas in which respondents had the greatest problems in re-acculturation. Most people had not problems in reconnecting with their own families, but the greatest problems were noticeable in re-adaptation to home societies and work places. Overall, the respondents had no great difficulties in re-adapting to their home cultures, as they all had very good jobs, which probably helped to reduce their stress upon arrival to their home cultures.

The analysed studies were dealing with research on intercultural competences in the span of eleven years (2000-2011). Most studies were analysed qualitatively and were focusing mainly on development of intercultural competences of individuals or small groups of people. These findings indicate that development of intercultural 
competences is a highly individual process, which cannot be generalized, as there are many factors (age, profession, social and cultural background, motivation, etc.) influencing development of intercultural competences. Also, each research was conducted in different environments with different types of respondents, different reasons and aims of development of intercultural competences. This is why the comparability between the studies is not feasible. Furthermore, there are no differences visible in the qualitative outcomes of the analysed studies in the eleven year span. Hence this implies that the general public has not naturally undergone any progress in terms of intercultural competence or sensitivity in this time span, and probably it cannot be expected that people would, without any interventions, obtain an ethnorelative approach. I would however claim, that intercultural trainings are becoming more popular and needed as the world of work and education becomes increasingly global. Therefore we may see an impact from this intervention in the future, so the area of intercultural competences will surely remain a topical subject for further research. Finally the analyses themselves suggest further options for investigation, and as the diversity seen within a highly interconnected world offers many varied research combinations of cultures and demographics, the possibilities for future research are virtually boundless.

Most people experiencing encounters with foreign cultures can find themselves in one or more models, going through various stages of intercultural competences. As suggested above, the process of acquiring intercultural competences is highly individual, which means that not all people go through developmental stages the same way or reach the same levels of intercultural sensitivity, maturity, adjustment and acculturation.

The paper includes research results gained as a part of the project KEGA 036UKF-4/2013

\section{References}

[1] L. A. Arasaratnam, and M. L. Doerfel, "Intercultural Communication Competence: Identifying Key Components from Multicultural Perspectives," International Journal of Intercultural Relations 29, 2005, 2: 137-163.

[2] D. K. Deardorff, The SAGE Handbook of Intercultural Competence, London: Sage Publications, 2009: 12-14.

[3] A. E. Fantini, "Language, Culture and Worldview: Exploring the Nexus," International Journal of Intercultural Relations 19, 1995, 19: 143-153.

[4] M. Byram, Teaching and Assessing Intercultural Communicative Competence, Clevedon, Philadelphia: Multilingual Matters, 1997: 31-43.

[5] J. W. Berry, et al. "Acculturation in plural societies," Applied Psychology: An International Review 38, 1998, 2: 185-206.

[6] P. M. King, and M. Baxter Magolda, "A Developmental Model of Intercultural Maturity," Journal of College Student Development 46, 2005, 6: 571-592.
[7] S. Lysgaard, "Adjustment in a Foreign Society: Norwegian Fulbright Grantees Visiting the United States," International Social Science Bulletin, 1955, 7: 45-51.

[8] J. T. Gullahorn, and J. E. Gullahorn, "An Extension of the U-Curve Hypothesis," Journal of Social Issues 19, 1963, 3: 33-47.

[9] M. J. Bennett, "Towards ethnorelativism: A Developmental Model of Intercultural Sensitivity," in: Education for the Intercultural Experience, ed. Michael Paige, Yarmouth, ME: Intercultural Press, 1993: 21-71.

[10] L. Cohen, et al., Research Methods in Education, Routledge, 2007: 289-296.

[11] R. Kegan, In over our Heads: The Mental Demands of Modern Life, Cambridge, MA: Harvard University Press, 1994: 181-363.

[12] M. Baxter Magolda, Knowing and Reasoning in College: Gender-related Patterns in Student' Intellectual Development, San Francisco: Jossey-Bass, 2004: 351.

[13] M. Baxter Magolda, "Self-authorship as the Common Goal of 21st Century Education," in Learning Partnerships: Theory and Models of Practice to Educate for Self-authorship. ed. Patricia King, Sterling, VA: Stylus, 2004: 1-35.

[14] V. Torres, "Factors Influencing Ethnic Identity Development of Latino College Students in the First Two Years of College," Journal of College Student Development 44, 2003, 4: 532 547.

[15] A. M. Ortiz, and R. A. Rhoads, "Deconstructing Whiteness as Part of a Multicultural Educational Framework: From Theory to Practice," Journal of College Student Development 41, 2000, 1: 81-93.

[16] D. Schoem, and S. Hurtado, Intergroup dialogue: Deliberative democracy in school, college, community, and workplace, MI: University of Michigan Press, 2001: 22-45.

[17] U. Stickler, and M. Emke, "Literalia: Towards Developing Intercultural Maturity Online", Language Learning \& Technology 15, 2011, 1: 147-168.

[18] D. O. Durocher, "Teaching Sensitivity to Cultural Difference in the First Year Foreign Language Classroom," Foreign Language Annals 40, 2007, 1: 143-160.

[19] A. U. Karim, "A Developmental Progression Model for Intercultural Consciousness: A Leadership Imperative," Journal of Education for Business 79, 2003, 1: 34-39.

[20] H. A. Marx, Please Mind the Gap: A Pre-service Teacher's Intercultural Development During a Study Abroad Program, BiblioBazaar, LLC, 2011: 82-149.

[21] K. Greendland, and R. Brown, "Acculturation and Contact in Japanese Students Studying in the United Kingdom," The Journal of Social Psychology 145, 2005, 4: 373-89.

[22] J. W. Berry, John, et al., Cross-Cultural Psychology: Research and Applications, Cambridge: Cambridge University Press, 2002: 307-335.

[23] F. W. Rudmin, and V. Ahmadzadeh, "Psychometric Critique of Acculturation Psychology: The Case of Iranian Migrants in Norway," Scandinavian Journal of Psychology 42, 2001, 1: 41-56. 
[24] R. M. Wielkiewicz, and L. W. Turkowski, "Reentry Issues Upon Returning From Study Abroad Programs," Journal of College Student Development 51, 2010, 6: 649-664.

[25] R. Pritchard, "Re-entry Trauma: Asian Re-integration After Study in the West," Journal of Studies in International
Education 15, 2011: 93-111.

[26] E. Reid, "Culture - an Inevitable Part of a Foreign Language Teaching," in Modernization of Teaching Foreign Languages, ed. Silvia Pokrivcakova, Brno: Masarykova Univerzita, 2010: 201-217. 